\title{
Inherited causes of exocrine pancreatic dysfunction
}

\author{
PETER R DURIE MD FRCPC
}

\begin{abstract}
PR DURIE. Inherited causes of exocrine pancreatic dysfunction. Can J Gastroenterol 1997;11(2):145-152. The exocrine pancreas is functionally immature at birth. Protease function is probably adequate, but lipase activity approximates $5 \%$ to $10 \%$ of adult values in the newborn and remains low in infancy. Pancreatic amylase secretion is essentially absent at birth and remains low through the first years of life. Functional disturbances of the exocrine pancreas are less frequent in childhood than in adult life. Causes of pancreatic dysfunction in childhood can be divided in two general categories: hereditary conditions, which directly affect the pancreas; and acquired disorders, in which loss of pancreatic function is a secondary phenomenon. Most inherited causes of pancreatic dysfunction are due to a generalized disorder. Cystic fibrosis is, by far, the most common inherited cause of disturbed pancreatic function among Caucasian children. All other inherited causes of exocrine pancreatic dysfunction (eg, Johanson-Blizzard syndrome) are uncommon or rare.
\end{abstract}

Key Words: Cystic fibrosis, Enzyme deficiencies, Exocrine pancreatic dysfunction, Johanson-Blizzard syndrome, Shwachman-Diamond syndrome

\section{Causes héréditaires de la dysfonction pancréatique exocrine}

RÉSUMÉ : La fonction exocrine du pancréas est immature à la naissance. La fonction de la protéase est probablement adéquate, mais l'activité de la lipase ne correspond qu'à 5 ou $10 \%$ environ des valeurs observées chez l'adulte et reste très discrète pendant la petite enfance. La sécrétion d'amylases pancréatiques est pour ainsi dire absente à la naissance et reste faible tout au long des premières années de vie. Les causes de la dysfonction exocrine du pancréas sont moins fréquentes durant l'enfance que durant la vie adulte. Les causes de la dysfonction pancréatique dans l'enfance peuvent se diviser en deux grandes catégories : les maladies héréditaires qui affectent directement le pancréas et les maladies acquises au cours desquelles la fonction pancréatique devient un phénomène secondaire. La plupart des causes héréditaires de la dysfonction pancréatique sont attribuables à une maladie générale : la mucoviscidose est de loin la maladie héréditaire la plus fréquente à causer une dysfonction pancréatique chez les enfants de race blanche. Toutes les causes héréditaires d'une dysfonction pancréatique exocrine (par ex., syndrome de Johanson-Blizzard) sont rares.
$\mathrm{T}$ he exocrine pancreas is functionally immature at birth. Protease function is probably adequate, but lipase activity approximates $5 \%$ to $10 \%$ of adult values in the newborn and remains low in infancy $(1,2)$. Pancreatic amylase secretion is essentially absent at birth and remains low through the first years of life. Thus, healthy infants younger than six months have significant 'physiological' steatorrhea (3). Except possibly in times of extreme metabolic or nutritional stress, pancreatic immaturity does not appear to be clinically important in infancy.

The exocrine pancreas has a large functional reserve. This was first demonstrated in adults in the classic studies of $\mathrm{Di}$ Magno et al (4) who demonstrated that pancreatic maldigestion did not occur until pancreatic enzyme secretion fell below $10 \%$ of control values. Using more sensitive enzyme assays (5) it was demonstrated that approximately $98 \%$ to

This paper was part of a symposium entitled 'Selected topics in pediatric gastroenterology and nutrition' held in October 1995 to honour the academic career of Dr Gordon G Forstner

Department of Pediatrics, University of Toronto; Division of Gastroenterology and Nutrition, The Research Institute, The Hospital for Sick Children, Toronto, Ontario

Correspondence and reprints: Dr Peter R Durie, Division of Gastroenterology/Nutrition, The Hospital for Sick Children, 555 University Avenue, Toronto, Ontario M5G 1X8. Telephone 416-813-6185, fax 416-813-6531 


\section{TABLE 1}

Causes of pancreatic dysfunction in childhood

\begin{tabular}{lccc}
\hline Hereditary & Approximate frequency & Acquired & Approximate frequency \\
\hline Cystic fibrosis & $>90 \%$ & Malnutrition & Unknown \\
Shwachman-Diamond & $\sim 3 \%$ & Tropical pancreatitis* & Variable \\
Johanson-Blizzard & Rare & Congenital viral infections & Rare \\
Pearson's bone marrow & Rare & Chronic enteropathy & Rare \\
Pancreatic agenesis/hypoplasia & Rare & Surgical excision & Rare \\
Isolated enzyme deficiencies & Rare & Chronic pancreatitis & Unknown \\
Hereditary pancreatitis & Rare & & \\
Metabolic pancreatitis & Rare & & \\
\hline
\end{tabular}

${ }^{*}$ Common in countries abutting the equator

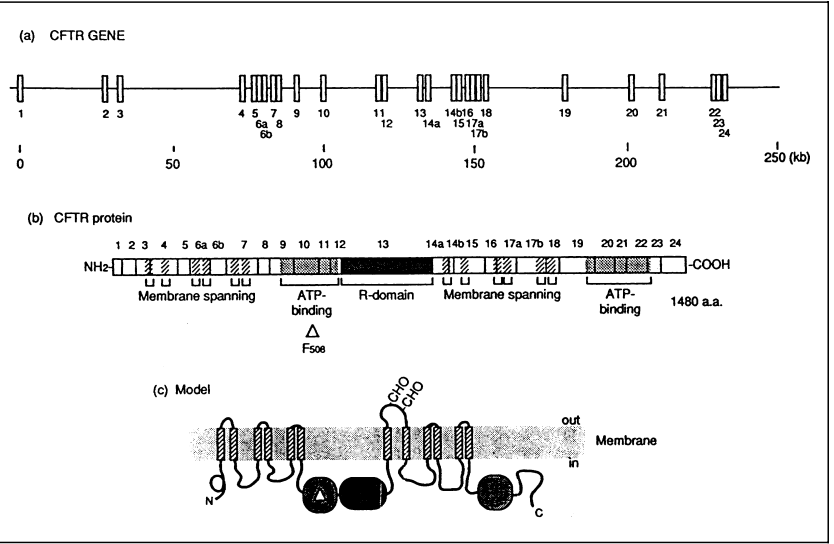

Figure 1) Schematic of the cystic fibrosis transmembrane conductance regulator (CFTR) gene and its protein product in the cell membrane. Six membrane spanning domains on each half of the molecule are depicted as cylinders. The spheres represent two nucleotide binding domains. The central, regulatory domain (R-domain), which contains individually charged amino acids, contains potential phosphorylation sites (PKA or PKC). N-glycosylation sites are indicated (CHO). The most common CFTR gene mutation ( $\triangle F 508)$ is in the first nucleotide binding domain. Reproduced with permission from Advances in Human Genetics 1991;20:153-8

$99 \%$ of enzyme secretory capacity must be lost before clinical evidence of malabsorption is evident. The term 'pancreatic insufficiency' (PI) is used to classify patients who have incurred such loss of exocrine function that they are unable to digest, and therefore assimilate, nutrients normally. By inference, symptoms of PI develop when more than $98 \%$ of pancreatic reserve is lost. 'Pancreatic sufficiency' (PS) describes pancreatic dysfunction where the pancreatic reserve remains above the threshold for developing signs and symptoms of maldigestion.

Functional disturbances of the exocrine pancreas are less frequent in childhood than in adult life, but there is a wide spectrum of causes. Causes of pancreatic dysfunction in childhood can be divided in two general categories: hereditary conditions, which directly affect the pancreas; and acquired disorders, in which loss of pancreatic function is a secondary phenomenon (Table 1). Most inherited causes of pancreatic dysfunction are due to a generalized disorder. Cystic fibrosis (CF) is, by far, the most common inherited cause of disturbed pancreatic function in Caucasian chil- dren. All other inherited causes of exocrine pancreatic dysfunction are uncommon or rare.

\section{CYSTIC FIBROSIS}

$\mathrm{CF}$, an inherited autosomal recessive disease affecting multiple secreting epithelial tissues, is most common in Caucasians, who have a carrier frequency of about $5 \%$. The much lower incidence in other races varies according to the degree of racial intermixing. The incidence in Caucasians is between 1:2000 and 1:3000 live births. Such a high frequency cannot be explained by random mutations which suggests the existence of a survival advantage for heterozygotes. Results from recent experiments in genetically created CF mice support the long-held hypothesis that heterozygous carriers of the CF gene mutation may be protected in infancy from the effects of cAMP-dependent toxigenic diarrhea, an illness previously associated with high infant mortality (6). The high sweat chloride concentration test is essential for diagnosis.

The electrolyte abnormalities in sweat reflect a secretory abnormality that affects all epithelial cells. In 1983, Quinton (7) first showed that chloride permeability was defective in the sweat duct; subsequently a similar defect was noted in the respiratory tract epithelium (8). Chloride channels present on the apical surface of various epithelia affected by CF do not respond to regulatory pathways involving cAMP (9). In 1989, the cDNA product of the CF gene was cloned and sequenced by Drs Lap-Chee Tsui and Jack Riordan at the University of Toronto in collaboration with Dr Frances Collins of the University of Michigan (10). The primary amino acid sequence of the gene product suggested the presence of two membranes spanning domains separated by two nucleotide binding folds and an intervening regulatory domain (Figure 1). Similarities between this protein and other membrane-associated 'transporter' proteins strongly supported the initial hypothesis that the gene product is a membrane channel. The protein product, the CF transmembrane conductance regulator (CFTR), has since been conclusively shown to be a cAMP-responsive chloride channel $(11,12)$. CFTR may have additional intracellular functions. The most common CFTR gene mutation, a three base-pair deletion, causes the loss of a single phenylalanine molecule at position 508 of the 1480 amino acid protein. This gene mutation, referred to as $\Delta \mathrm{F} 508$, occurs in approximately $69 \%$ of Canadian and 
American CF chromosomes (13). More than 600 CFTR gene mutations have since been described. Most are infrequent or rare; others are clearly 'private' mutations.

Many of the manifestations of CF result from poor intraluminal hydration of macromolecules within ducts used by epithelial cells (Figure 2). Mucous secretions in the bronchi and intestine are viscid and inspissated. Certain glands, such as the pancreas and vas deferens, appear to be most vulnerable to flow-related problems because of their tortuosity, the length of their ducts, the high macromolecule concentration of their secretions and their dependence on the CFTR chloride channel for fluid secretion (14). There is good pathological evidence to suggest that organ damage arises as a result of ductal or glandular plugging by macromolecules that have gelled or precipitated in concentrated secretions. Figure 3 illustrates how pancreatic ductular secretions become concentrated due to the failure of anion (chloride and bicarbonate) secretion in the exocrine pancreas $(15,16)$. In contrast, the sweat gland is not affected pathologically, despite that the sweat duct epithelium is abnormal from an electrophysiological perspective. The lack of protein or other macromolecules within the sweat duct secretions probably protects it from pathological damage.

Genotypes and phenotypes: It has long been recognized that the onset of symptoms and the degree of involvement and rate of progression of disease in affected organs varies considerably from patient to patient. This variability has been difficult to explain. Patterns of clinical symptoms are almost certainly influenced by multiple contributing factors including genetic, environmental and varying management strategies. In an attempt to make predictions of disease severity on the basis of particular CFTR gene mutations, patients' genotypes and their corresponding phenotypes have been analyzed. Perhaps the most striking observation is that genetic factors influence the degree of pancreatic disease and its rate of progression. Cross-sectional analyses of large CF populations reveal that approximately $85 \%$ of patients have PI and require pancreatic enzymes supplements with meals. The remainder have PS and do not need pancreatic enzyme supplements. PS, an operational term, reflects the ability of such patients to digest normally without enzyme supplements. All PS patients with CF have decreased fluid and electrolyte secretion, and a large percentage have reduced enzyme secretion due to pancreatic damage $(15,16)$. As a group, CF patients with PS are diagnosed at a later age, experience milder symptoms, particularly with respect to lung disease, and have a superior overall prognosis in terms of survival than those with PI (17). Interestingly, patients with PS have abnormal mean sweat chloride concentrations but the concentrations are lower than those of patients with PI.

Before the CF gene was cloned, genetic differences were suggested by a striking concordance of pancreatic function status (PS or PI) among families with more than one affected case (18) and by the association of PS or PI status with specific genetic haplotypes (19). Subsequently it was shown that severe pancreatic disease is strongly associated with the presence of $\Delta \mathrm{F} 508$ (35), and $99 \%$ of those homozygous for

\section{The Pathophysiology of Cystic Fibrosis}

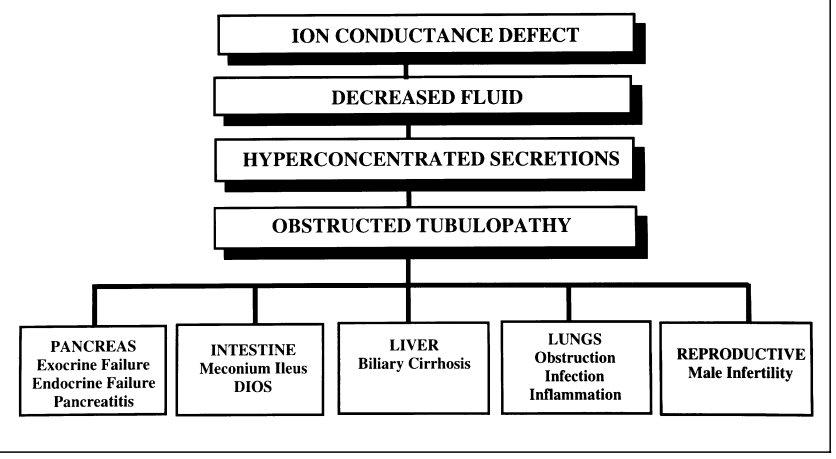

Figure 2) Pathophysiology of cystic fibrosis. Many of the manifestations of cystic fibrosis are due to reduced fluid secretion which prevents ductal lumina from maintaining macromolecules in solution or suspension. Secretions tend to be viscid, which obstruct ducts causing organ damage. DIOS Distal intestinal obstruction syndrome

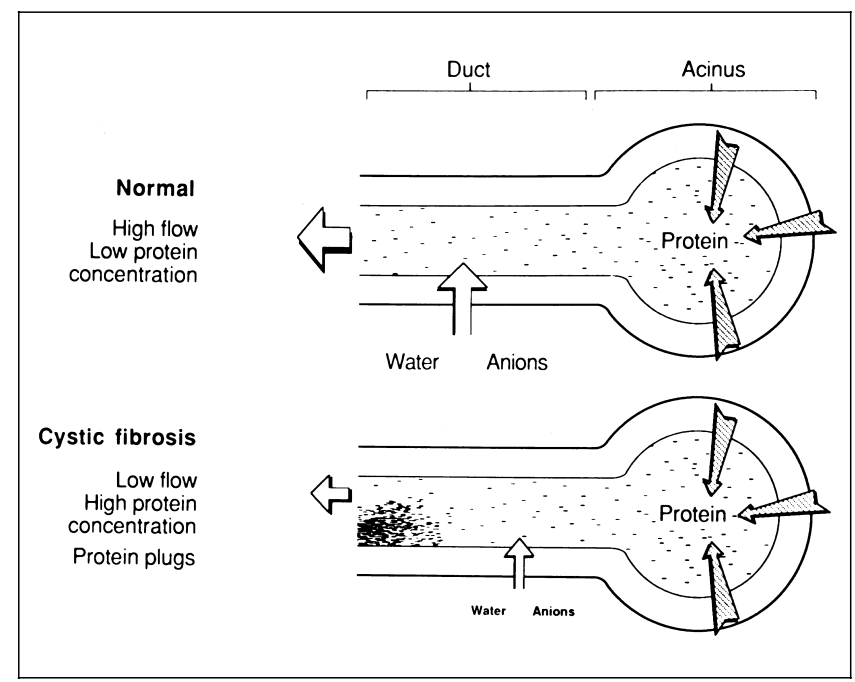

Figure 3) Pathophysiology of the cystic fibrosis (CF) pancreas. Unlike the situation in the normal pancreas, where proteinaceous secretions are maintained in solution by ductal secretion of anions and fluid, the CF pancreas possesses greatly reduced ductal fluid flow due to CF transmembrane conductance regulator dysfunction or its absence. High concentrations of protein secreted by acinar cells will precipitate in small pancreatic ducts causing plugging. Reproduced with permission from reference 14

the most common mutation had PI (20). Kristidis and colleagues (21) have since screened a large patient cohort for additional CFTR gene mutations. Remarkably, each genotype was associated with either PI or PS (not both). On this basis they classified mutations as 'severe' or 'mild' with respect to pancreatic function status (Table 2). A severe mutation combined with any other severe mutation is associated with PI. In contrast, $\Delta \mathrm{F} 508$ (or any other severe mutation) when combined with a mild mutation (or two mild mutations) is invariably associated with PS. Thus, mild alleles have a dominant effect over a severe allele. All nonsense, splice junction and frameshift mutations appear to be severe. Missense mutations caused by single nucleotide changes and alternate splicing mutations can be severe or mild. 
TABLE 2

Classification of cystic fibrosis gene mutations as 'severe' or 'mild' with respect to pancreatic function

\begin{tabular}{cll}
\hline Type of mutation & Severe (location) & Mild (location) \\
\hline Missense & 1148T (exon 4) & R117H (exon 4) \\
(point mutation) & G480C (exon 9) & R334W (exon 7) \\
& V520F (exon 10) & R347P (exon 7) \\
& G551D (exon 11) & A455E (exon 9) \\
& R560T (exon 11) & P574H (exon 12) \\
& N1303K (exon 21) & \\
Single amino acid & SF508 (exon 10) & \\
deletion & $\Delta$ I507 (exon 10) & \\
Stop codon & Q493X (exon 10) \\
(nonsense) & G542X (exon 11) & \\
& R553X (exon 11) & \\
Splice junction & W1282X (exon 20) & \\
Frameshift & 621+1G $\rightarrow$ T (intron 4) & \\
& 1717-1G $\rightarrow$ T (intron 10) & \\
\hline
\end{tabular}

Severe mutations result in severe pancreatic disease, usually pancreatic insufficiency. Mild mutations result in pancreatic sufficiency. Based on reference 21

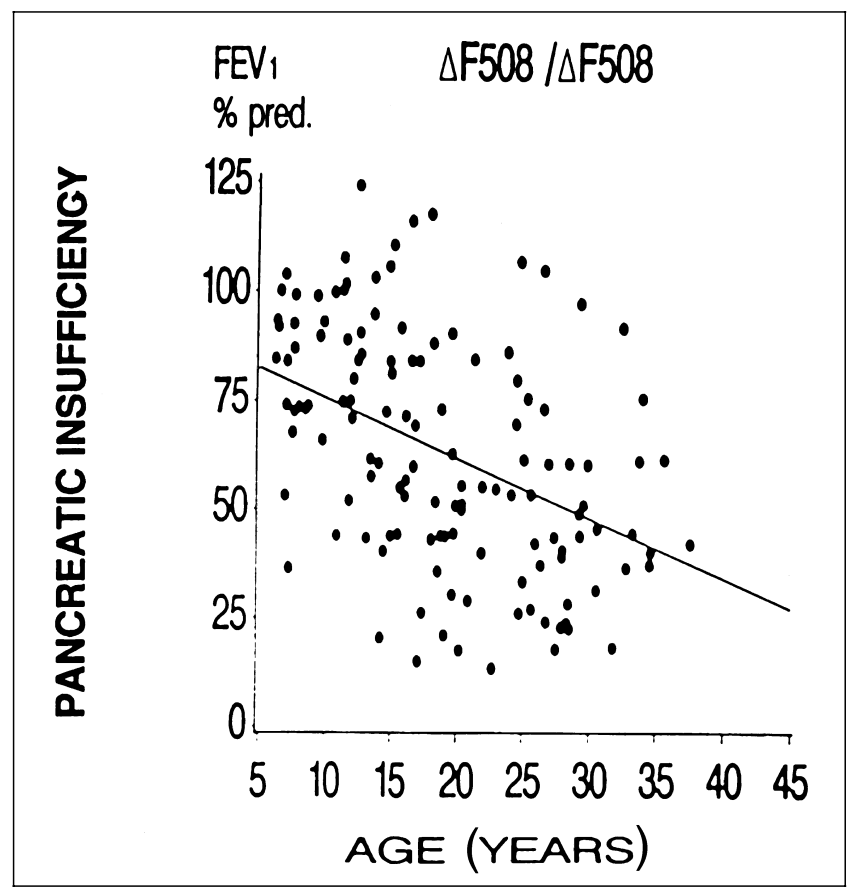

Figure 4) Pulmonary disease in cystic fibrosis (CF). Pulmonary function (forced expiratory volume in $1 \mathrm{~s}\left[\mathrm{FEV}_{1}\right]$ ) plotted against age in $\mathrm{CF}$ patients homozygous for the $\Delta F 508$ mutation. There is a wide range of severity of pulmonary function, ranging from normal $\mathrm{FEV}_{1}$ to severely compromised lung disease, even in adult patients with the same genotype. Reproduced with permission from reference 20

Correlations between mutations and other phenotypic manifestations are less clear-cut. Meconium ileus appears to be strongly associated with PI mutations, but with variable expression $(20,22)$. In addition, CF-associated liver disease is more likely to be present in patients with the severe PI mutations. The severity of lung disease and its rate of progression is less easily defined by genotype. As shown in Figure
4, patients carrying $\Delta 508$ on both alleles can have widely variable lung function at the same age (20). Although PS patients tend to have milder pulmonary disease, it appears that environmental, infectious and possibly other genetic factors unrelated to the CFTR gene may influence the severity of lung disease.

Diagnosis and clinical course: Twelve to $15 \%$ of patients with CF present at birth show signs and symptoms of intestinal obstruction due to meconium ileus (22). Approximately $60 \%$ of patients are diagnosed in the first year of life, and more than $85 \%$ are diagnosed before age five years. In infancy, failure to thrive, frequent foul stools or rectal prolapse should suggest the diagnosis. At clinical presentation signs and symptoms of chest disease may be absent or very mild. Increased appetite may compensate for stool energy losses, and patients may thrive. Profound malnutrition, with hypoalbuminemia, edema and anemia, is a relatively dramatic complication occurring most frequently between three and four months of age. It is now quite common for the diagnosis to be established for the first time in adulthood. In older patients, primary presenting manifestations may include male infertility, liver disease or recurrent pancreatitis.

Over the past three decades there has been a dramatic improvement in median survival among CF patients. The vast majority of patients now survive, in remarkably good health, into adulthood. Current analyses of large CF populations show median survival to approximately 30 years. Females with $\mathrm{CF}$, however, show consistently poorer survival (23).

In more than $90 \%$ of patients, disease outcome depends upon pulmonary complications. Although the CF lung is normal at birth, chronic pulmonary infections with inflammation develop at a very young age. Eventually this leads to widespread destruction of terminal bronchioles and to bronchiectasis, emphysema and cor pulmonale. There appears to be a direct association between the degree of undernutrition and the severity of pulmonary disease. A much smaller percentage of patients die of complications of CF-associated liver disease.

Pancreatic disease: Pancreatic damage begins to develop in utero with the accumulation of proteinaceous secretory material within small pancreatic ducts. This obstructive process causes dilation of the ductal lumina, followed by progressive acinar atrophy, fatty replacement and interstitial fibrosis (24). In those with PI advanced acinar destruction is present. Endocrine tissue is relatively preserved initially, but with advancing age patients with PI develop loss of pancreatic islets. Clinical symptoms of diabetes mellitus or biochemical evidence of glucose intolerance may be present in up to $50 \%$ of adolescents or adults with CF (25). In patients with the PS genotype, progression of pancreatic disease either does not occur or seems to be retarded. All CF patients have impaired pancreatic fluid secretion as a result of defective anion transport within the pancreatic ducts $(15,16)$. Clearly the severity of the problem varies between PS and PI patients. It is noteworthy that patients with PS are susceptible to acute recurrent pancreatitis (26). In the author's experience, $8 \%$ to 
$10 \%$ of patients with the PS phenotype develop this complication, almost certainly because they have sufficient residual pancreatic tissue to promote an active inflammatory response. Frequently the diagnosis of $\mathrm{CF}$ is first established in young adults solely with symptoms of recurrent pancreatitis.

\section{SHWACHMAN-DIAMOND SYNDROME}

The Shwachman-Diamond syndrome was first described in 1964 (27). Next to CF it is the most common inherited form of exocrine pancreatic dysfunction (28-30). The syndrome is characterized by exocrine dysfunction, short stature, variable hematological features and radiological skeletal changes (Table 3). The precise etiology of this multisystem disease is unknown. Published studies of segregation ratios and family pedigrees support an autosomal recessive mode of inheritance. However, there have been documented cases of affected parents and children. Possibly an autosomal dominant pattern with variable expression is present in some families. Pancreatic disease: Pancreatic dysfunction of variable severity is a consistent feature of Shwachman-Diamond syndrome. The pancreatic lesion appears to be due to failure of pancreatic acinar development. Pathologically there is extensive fatty replacement of pancreatic acinar tissue and normal ductular architecture. Pancreatic function studies using intravenous secretin and cholecystokinin confirmed the presence of markedly impaired enzyme secretion but preserved ductal function $(15,30)$.

The vast majority of patients have symptoms of maldigestion from birth due to PI. Approximately $50 \%$ of patients appear to exhibit a modest improvement in enzyme secretion with advancing age (30). Consequently, a number of older patients with Shwachman-Diamond syndrome actually develop PS with normal fat absorption when assessed by $72 \mathrm{~h}$ fecal fat balance studies. Pancreatic function testing of most patients with PS shows markedly reduced pancreatic enzyme secretion, averaging $10 \%$ to $14 \%$ of normal. The absence of steatorrhea, therefore, does not exclude a diagnosis of Shwachman-Diamond syndrome. If ShwachmanDiamond syndrome is suspected, a quantitative pancreatic function test should be performed. Alternatively, computed tomography of the pancreas may demonstrate fatty changes within the body of the pancreas (Figure 5). A low serum immunoreactive trypsinogen concentration is highly suggestive of severe pancreatic exocrine deficiency (31).

Hematological alterations: Hematological abnormalities vary considerably from patient to patient. Furthermore, in an individual patient the severity of the hematological picture may show temporal periodicity. Bone marrow dysfunction may involve neutropenia, red cell hypoplasia or thrombocytopenia, or a combination. Intermittent or persistent neutropenia, the most frequent hematological finding, is present in virtually all patients. Thrombocytopenia and red cell hypoplasia are slightly less common. Due to the intermittent nature of neutropenia, it is recommended that repeated blood counts be performed at least biweekly over three weeks when the patient is free from infection. Bone marrow aspirates
TABLE 3

\section{Clinical features of Shwachman-Diamond syndrome}

$\begin{array}{ll}\text { Pancreatic } & \text { Exocrine pancreatic hypoplasia } \\ \text { Hematological } & \text { Neutropenia (persistent or intermittent) } \\ & \text { Red cell hypoplasia } \\ & \text { Thrombocytopenia } \\ & \text { Pancytopenia } \\ & \text { Elevated fetal hemoglobin } \\ & \text { Myelo-lymphoproliferation diseases } \\ & \text { Metaphyseal dysplasia } \\ \text { Skeletal } & \text { Long bone tubulation } \\ & \text { Short or flared ribs } \\ & \text { Thoracic dystrophy } \\ & \text { Clinodactyly } \\ & \text { Short stature (normal growth velocity) } \\ \text { Growth } & \text { Psychomotor delay } \\ \text { Other } & \text { Renal tubular dysfunction } \\ & \text { Diabetes mellitus } \\ & \text { Dental abnormalities } \\ & \text { Ichthyosis } \\ & \text { Hepatomegaly } \\ & \text { Hirschsprung's disease }\end{array}$

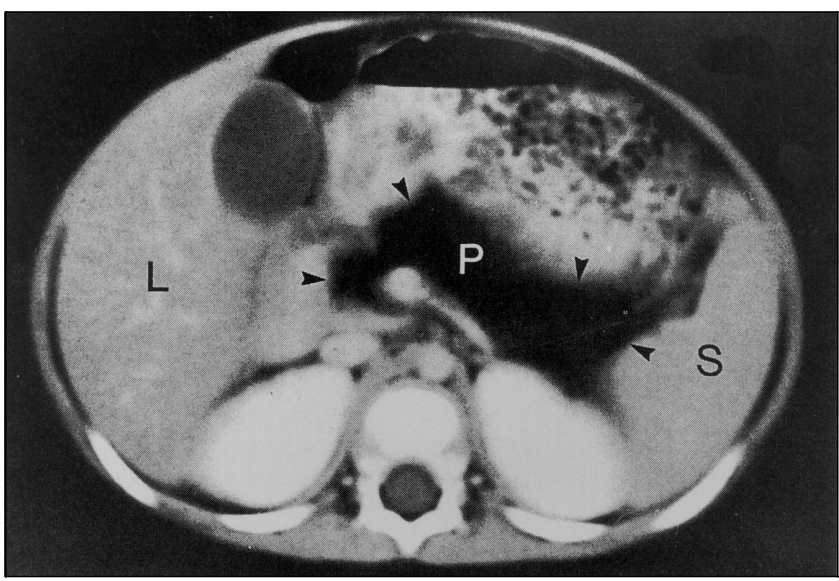

Figure 5) Computed tomography scan of the abdomen after intravenous contrast injection of a patient with Shwachman-Diamond syndrome. This two-year-old patient presented with massive hepatomegaly and intermittent neutropenia. Marked fatty infiltration of the exocrine pancreas is outlined $(P)$ with arrowheads. This is in contrast to soft density of the liver $(L)$ and spleen $(S)$. Reproduced with permission from J Pediatr Gastroenterol Nutr 1994;19:111-3

reveal varying degrees of marrow hypoplasia, fat infiltration and myeloid maturation arrest. Several studies have also provided evidence of a neutrophil migration defect that does not appear to be caused by malnutrition. Patients with Shwachman-Diamond syndrome are particularly susceptible to severe infections including otitis media, bronchopneumonia, osteomyelitis, septicemia and recurrent skin infections. Overwhelming sepsis is a well recognized fatal complication of this disorder, particularly early in life.

A significant percentage of patients with ShwachmanDiamond syndrome develop lymphoproliferative and myeloproliferative malignancies (32). Those with myeloproliferative malignancies are usually unresponsive to standard 


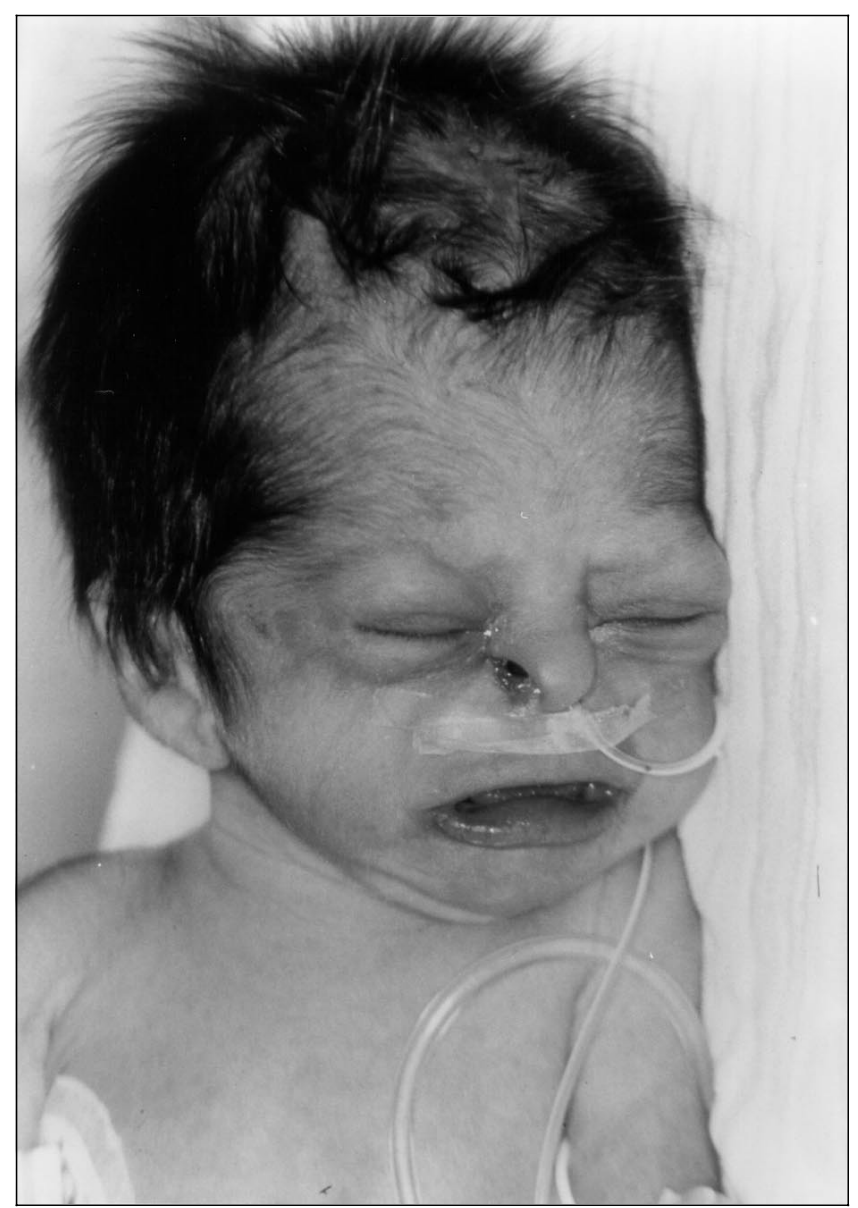

Figure 6) Typical facial characteristics of a female patient with Johanson-Blizzard syndrome. There is absence of the nasi alae and a scalp defect

chemotherapy and unless bone marrow transplantation is performed, this complication is invariably fatal.

Short stature: Short stature is a consistent clinical feature of Shwachman-Diamond syndrome. Most patients are well nourished but remain consistently below the third percentile for height and weight. In treated patients growth velocity is normal. Some patients have evidence of delayed puberty. The occasional adult achieves the 25 th percentile for height. Skeletal abnormalities: Skeletal abnormalities are quite variable. Some patients present at birth with thoracic dystrophy, while others have short flared ribs. Metaphyseal dysostosis of the long bones is a common radiological abnormality, particularly in the femoral head and the proximal tibia. These changes may not be detectable until after 12 months of age. The etiology of the metaphyseal changes is unclear but disorders of endochondrial ossification have been suggested. In the majority of patients these bony lesions fail to produce any symptoms. However, the integrity of the growth plate may be affected, which in turn may result in skeletal growth disturbances and joint deformities, particularly in the knees and hips.

Other manifestations: Additional, less frequent, features felt to be associated with Shwachman-Diamond syndrome include psychomotor delay, hypotonia, massive hepatomegaly, elevated transaminase levels in the absence of hepatomegaly, dental abnormalities, endocardial fibrosis, renal tubular acidosis and diabetes mellitus (9).

\section{JOHANSON-BLIZZARD SYNDROME}

The Johanson-Blizzard syndrome is a rare, multisystem, autosomal recessive condition first described by Johanson and Blizzard in 1971 (33). Individual patients have a variable, multisystem phenotype including aplasia of the nasi alae, deafness, hypothyroidism, absent permanent teeth, scalp defects and pancreatic exocrine insufficiency. Developmental delay, along with genitourinary, cardiac and anorectal malformations, may also occur. Death in infancy due to severe malabsorption is frequent. The clinical hallmarks of this syndrome, particularly agenesis of the nasal cartilage, make detection of this syndrome reasonably obvious (Figure 6). The absence of bone marrow and skeletal changes differentiate it from Shwachman-Diamond syndrome.

Jones et al (34) recently defined the pancreatic condition in two patients with Johanson-Blizzard syndrome. Evaluation by quantitative pancreatic function testing revealed markedly reduced enzyme secretion (trypsin, colipase and lipase), which was within the pancreatic insufficient range. The level of enzyme secretion in these patients was similar to that obtained in young Shwachman-Diamond syndrome patients with PI. When assessed in relation to acinar secretion, mean pancreatic ductal fluid and anion (chloride and bicarbonate) secretion in patients with Johanson-Blizzard syndrome appeared similar to levels in patients with Shwachman-Diamond syndrome. This finding contrasts with the observation in CF patients, who have a primary defect of anion secretion within pancreatic ducts, which in turn markedly decreases secretion of ductal electrolytes and fluid. Thus, the pancreatic defect in Johanson-Blizzard syndrome appears to be similar to that of Shwachman-Diamond syndrome - evidence of primary acinar cell failure but preserved ductal function. Very low or absent serum immunoreactive trypsinogen concentrations occur in infants with Johanson-Blizzard syndrome and PI. Whether patients with Johanson-Blizzard syndrome show improvement of pancreatic function with advancing age is unknown.

\section{EXOCRINE PANCREATIC DYSFUNCTION WITH REFRACTORY SIDEROBLASTIC ANEMIA}

First described by Pearson and colleagues (35) in 1979, exocrine pancreatic dysfunction with refractory sideroblastic anemia is a rare syndrome characterized by refractory sideroblastic anemia, vacuolization of bone marrow precursors and exocrine pancreatic dysfunction. Shortly after birth there is macrocytic anemia with variable degrees of neutropenia and thrombocytopenia. The bone marrow abnormalities are quite different from those seen in Shwachman-Diamond syndrome. Bone marrow aspirates reveal striking vacuolization of the erythroid and myeloid precursors together with a severe degree of hemosiderosis and ringed sideroblasts.

Patients develop severe failure to thrive and require regular blood transfusions. Qualitative pancreatic function tests revealed depressed acinar function and reduced fluid and 
electrolyte secretion. Some patients die in infancy of sepsis, while others appear to improve spontaneously with reduced requirements for blood transfusion. Autopsy examination of the pancreas reveals acinar cell atrophy and fibrosis. Fatty infiltration is not a prominent feature. The need for long term pancreatic enzyme replacement therapy has not been elucidated.

\section{ISOLATED ENZYME DEFICIENCIES}

Several reports of isolated deficiencies of exocrine pancreatic enzymes have been described. These include isolated lipase deficiency, lipase-colipase deficiency, isolated colipase deficiency, trypsinogen deficiency and amylase deficiency. All are extremely rare, but in some instances the validity of the observations are hampered by the insufficient sensitivity and specificity of the pancreatic function tests and enzyme assays.

Eleven cases of isolated lipase deficiency have been described, including the first four patients described by Sheldon in 1964 (36). All these patients had documented steatorrhea that responded to pancreatic enzyme replacement therapy. Closer analysis of Sheldon's report, however, reveals that unstimulated duodenal juice was analyzed; there was low lipase activity, and in three cases, low amylase levels and trypsin activity. CF was excluded in three patients, but a fourth was noted to have a borderline sweat chloride result. Subsequently, in one case described by Figarella et al (37) stimulated pancreatic secretions were obtained. The investigators were unable to detect lipase by sensitive immunoassay but pancreatic colipase was present. Hildebrand et al (38) reported two siblings with normal lipase secretion but isolated colipase deficiency. Ghishan et al (39) demonstrated a single patient with combined lipase and colipase deficiency.

Townes and co-workers (40) reported two children with trypsinogen deficiency, both of whom presented with growth failure, hypoproteinemia and edema. CF was excluded by appropriate testing. Proteolytic enzyme activity was absent, but due to technical limitations of the testing procedure it was difficult to assess the precise defect. It is possible that one or both of these cases had enterokinase deficiency.

Whether congenital amylase deficiency is a true entity remains debatable. It is well known that pancreatic amylase secretion is markedly deficient in infancy. In the cases described in the literature (41) there is no evidence that the isolated amylase deficiency was permanent, and the cases may represent the normal process of postnatal maturation of amylase secretion.

\section{PANCREATIC DYSFUNCTION DUE TO INHERITED PANCREATITIS}

In childhood, acute and chronic pancreatitis can be due to a variety of hereditary, congenital, toxic and environmental causes (42). Only inherited causes of childhood-onset pancreatitis are discussed here. Although detailed information is lacking about pancreatitis in childhood, it is estimated that idiopathic chronic pancreatitis accounts for approximately $25 \%$ of all cases. Some of these patients may possess an unrecognized inherited disorder. It must be emphasized that $\mathrm{PI}$ is a late consequence of chronic pancreatitis, taking years, even decades, for the exocrine pancreas to fail as a digestive organ.

Hereditary pancreatitis: First described by Comfort and Steinberg in 1952 (43), hereditary pancreatitis has been reported in more than 200 patients from a number of pedigrees in North America, Europe and Japan. Although early studies raised doubts about the mode of inheritance, subsequent reports have confirmed an autosomal dominant pattern of inheritance (44). The degree of penetrance varies between pedigrees. Differentiation from other forms of chronic pancreatitis is usually not difficult, owing to the early onset of symptoms and the presence of multiple affected relatives. Recently Whitcomb et al (45) reported that a single amino acid substitution at residue 117 of the cationic trypsinogen gene is associated with hereditary pancreatitis. Experimental studies suggest that the mutation permits trypsinogen to autoactivate within the acinar cell, resulting in pancreatitis.

Pathological examination of patients with long-standing pancreatitis reveals chronic calcific pancreatitis similar to other forms of chronic calcific pancreatitis. Autopsy specimens reveal a shrunken fibrotic pancreas, frequently with small proteinaceous plugs and calculi within the ducts. In this sense the pathological features of this disease resemble CF.

In the majority of cases of hereditary pancreatitis, symptoms first occur in childhood, but occasionally first manifest in early adulthood (46). Its onset is characterized by severe bouts of recurrent pancreatitis which then vary in frequency and severity. Between episodes patients are well. With disease progression symptoms resemble all forms of chronic pancreatitis. The pancreas is eventually destroyed, and the frequency and severity of attacks of abdominal pain usually decrease. Diabetes mellitus is common, affecting 10\% to $25 \%$ of patients with chronic pancreatitis. Malabsorption due to PI has been reported in 5\% to $50 \%$ of patients; owing to the large functional reserve of the exocrine pancreas, pancreatic failure is a late complication.

Metabolic causes of chronic pancreatitis: A variety of rare metabolic disorders can cause chronic pancreatitis. These rare disorders include CF patients with PS, hypercalcemia, certain hyperlipidemic conditions and a variety of organic acidemias (42). Hyperlipidemia appears to be more commonly associated with recurrent acute pancreatitis but chronic pancreatitis has been reported in type I and type $\mathrm{V}$ conditions. CF patients can develop chronic calcific pancreatitis with typical clinical symptoms and pathological characteristics of intraductal plugging, calculi and chronic inflammation. A report of chronic pancreatitis in a patient with alpha 1 antitrypsin deficiency has also been described but the significance of this association remains unclear. Acute recurrent pancreatitis and chronic pancreatitis are now recognized complications of patients with branchedchain organic acidemias (47). These include patients with methylmalonic acidemia, isovaleric acidemia and single case of a patient with maple syrup urine disease. 
ACKNOWLEDGEMENTS: The author acknowledges Dr Gordon Forstner's remarkable contributions to our understanding of inherited exocrine pancreatic disorders. Many of the data contained in this manuscript arose from his direct contribution to the field.

\section{REFERENCES}

1. Zoppi G, Andreotti G, Pajno-Ferrara F, Njai DM, Gaburro D. Exocrine pancreas function in premature and full term neonates. Pediatr Res 1972;6:880-6.

2. Lebenthal E, Lee PC. Development of the functional response in human exocrine pancreas. Pediatrics 1980;66:556-60.

3. Fomon SJ, Ziegler ER, Thomas LN, Jensen RL, Filer RJ. Excretion of fat by normal full-term infants fed various milks and formulas. Am J Clin Nutr 1970;23:1299-313.

4. DiMagno EP, Go VLW, Summerskill WHJ. Relations between pancreatic enzyme outputs and malabsorption in severe pancreatic insufficiency. N Engl J Med 1973;288:813-5.

5. Gaskin KJ, Durie P, Lee L, Hill R, Forstner GG. Colipase and lipase secretion in childhood onset pancreatic insufficiency: delineation of patients with steatorrhea secondary to relative colipase deficiency. Gastroenterology 1984;86:1-7.

6. Gabriel S, Brigman KN, Koller BH, Boucher RC, Stutts MJ. Cystic fibrosis heterozygote resistance to cholera toxin in the cystic fibrosis mouse model. Science 1994;266:107-9.

7. Quinton PM. Chloride impermeability in cystic fibrosis. Nature 1983;301:421-2.

8. Knowles MR, Gatzy JT, Boucher RC. Relative ion permeability of normal and cystic fibrosis nasal epithelium. J Clin Invest 1983;71:1410-7.

9. Sato K, Sato F. Defective beta adrenergic response of cystic fibrosis sweat glands in vivo and in vitro. J Clin Invest 1984;73:1763-71.

10. Riordan JR, Rommens JM, Kerem B-S, et al. Identification of the cystic fibrosis gene: cloning and characterization of complementary DNA. Science 1989;245:1066-73.

11. Anderson MP, Rich DP, Rich JGR, Smith AE, Welsh MJ. Generation of cAMP-activated chloride currents by expression of CFTR. Science 1991;251:679-82.

12. Bear CE, Li C, Kartner N, et al. Purification and functional reconstitution of the cystic fibrosis transmembrane conductance regulator (CFTR). Cell 1992;68:809-18.

13. Kerem B-S, Rommens JM, Buchanan JA, et al. Identification of the cystic fibrosis gene: genetic analysis. Science 1989;245:1073-80.

14. Forstner G, Durie PR. Cystic fibrosis. In: Walker WA, Durie PR, Hamilton JR, Walker-Smith JA, Watkins JB, eds. Pediatric Gastrointestinal Disease: Pathophysiology, Diagnosis, Management, 2nd edn. Philadelphia: Mosby, 1996:1466-87.

15. Kopelman H, Corey M, Gaskin K, Durie P, Weizman Z, Forstner G. Impaired chloride secretion as well as bicarbonate secretion, underlies the fluid secretory defect in the cystic fibrosis pancreas. Gastroenterology 1988;95:349-55.

16. Kopelman H, Durie P, Gaskin K, Weizman Z, Forstner G. Pancreatic fluid secretion and protein hyperconcentration in cystic fibrosis. N Engl J Med 1985;312:329-34.

17. Gaskin K, Gurwitz D, Durie PR, Levison H, Forstner G. Improved respiratory prognosis in patients with cystic fibrosis with normal fat absorption. J Pediatr 1982;100:857-62.

18. Corey ML, Durie PR, Moore D, Forstner G, Levison H. Familial concordance of pancreatic function in cystic fibrosis. J Pediatr 1989;115:274-7.

19. Kerem B-S, Buchanan JA, Durie P, et al. DNA marker haplotype association with pancreatic sufficiency in cystic fibrosis. Am J Hum Genet 1989;44:827-34.

20. Kerem E, Corey M, Kerem B-S, et al. The relation between genotype and phenotype in cystic fibrosis - analysis of the most common mutation $(\Delta \mathrm{F} 508)$. N Engl J Med 1990;323:1517-22.

21. Kristidis P, Bozon D, Corey M, et al. Genetic determination of pancreatic function. Am J Hum Genet 1992;50:1178-84.

22. Kerem E, Corey B, Kerem B-S, Durie P, Tsui L-C, Levison H.
Clinical and genetic comparisons of patients with cystic fibrosis with or without meconium ileus. J Pediatr 114:767-73.

23. Corey ML. Longitudinal studies in cystic fibrosis. In: Sturgess J, ed. Perspectives in Cystic Fibrosis. Proceedings of the Eighth International Congress on Cystic Fibrosis. Mississauga: Imperial Press, 1980:246.

24. Oppenheimer E, Esterly J. Cystic fibrosis of the pancreas. Arch Pathol 1973;96:149-54

25. Dodge JA, Morrison G. Diabetes mellitus in cystic fibrosis: a review. J Roy Soc Med 1992;85(Suppl 19):25-8.

26. Shwachman H, Lebanthal E, Khaw K-T. Recurrent acute pancreatitis in patients with cystic fibrosis with normal pancreatic enzymes. Pediatrics 1975;55:86-95.

27. Shwachman H, Diamond LK, Oski FA, Khaw K-T. The syndrome of pancreatic insufficiency and bone marrow dysfunction. J Pediatr 1964;65:645-63.

28. Bodian M, Sheldon W, Lightwood R. Congenital hypoplasia of the exocrine pancreas. Acta Pediatr Scand 1964;53:282-93.

29. Aggett PJ, Cavanagh NPC, Matthew DJ, Pincott JR, Sutcliffe J, Harries JT. Shwachman's syndrome. Arch Dis Child 1980;55:331-47.

30. Mack DR, Forstner GG, Wilschanik M, Freedman MH, Durie PR. Shwachman syndrome: Exocrine pancreatic dysfunction and variable phenotypic expression. Gastroenterology 1996;111:1593-602.

31. Moore DJ, Forstner GG, Largman C, Cleghorn GJ, Wong SS, Durie PR. Serum immunoreactive trypsinogen: a useful indicator of severe exocrine pancreatic dysfunction in the pediatric patient without cystic fibrosis. Gut 1986;27:1362-8.

32. Woods WG, Roloff JS, Lukens JN, Krivit W. The occurrence of leukemia in patients with Shwachman syndrome. J Pediatr 1981;99:425-8.

33. Johanson A, Blizzard R. A syndrome of congenital aplasia of the alae nasi, deafness, hypothyroidism, dwarfism, absent permanent teeth and malabsorption. J Pediatr 1971;79:982.

34. Jones NL, Hofley PM, Durie PR. Pathophysiology of the pancreatic defect in Johanson Blizzard syndrome - a disorder of acinar development. J Pediatr 1994;125:406-8.

35. Pearson HA, Lobel JS, Kocoshis SA, Naiman JL, Hoffman R, Marsh JC. A new syndrome of refractory sideroblastic anemia with vacuolization of marrow precursors and exocrine pancreatic dysfunction. J Pediatr 1979;95:976-84.

36. Sheldon W. Congenital lipase deficiency. Arch Dis Child 1964;39:268-71.

37. Figarella C, De Caro A, Leupold D, Poley J. Congenital pancreatic lipase deficiency. J Pediatr 1980;96:412-6.

38. Hildebrand H, Borgström B, Békássy A, Erlanson-Albertsson C, Helin I. Isolated colipase deficiency in two brothers. Gut 1982;23:243-6.

39. Ghishan FK, Moran JR, Durie P, Greene HL. Isolated congenital lipase-colipase deficiency. Gastroenterology 1984;86:1580-2.

40. Townes PL, Bryson MF, Miller G. Further observations on trypsinogen deficiency disease: report of a second case. J Pediatr 1967;71:220-4.

41. Lowe CV, May DC. Selective pancreatic deficiency: absent amylase, deficient trypsin and normal lipase. Am J Dis Child 1951;82:459-64.

42. Robertson MA, Durie PR. Pancreatitis. In: Walker WA, Durie PR, Hamilton JR, Walker-Smith JA, Watkins JD, eds. Pediatric Gastrointestinal Disease. Pathophysiology, Diagnosis, Management, 2nd edn. Philadelphia: Mosby, 1996:1436-65.

43. Comfort MW, Steinberg AG. The pedigree of a family with chronic relapsing pancreatitis. Gastroenterology 1952;21:54-63.

44. Kattwinkel J, Lapey A, di Sant'Agnese PA, Edwards WA, Hufty MP. Hereditary pancreatitis: three new kindreds and a critical review of the literature. Pediatrics 1973;52:55-69.

45. Whitcomb DC, Gorry MC, Preston RA, et al. Hereditary pancreatitis is caused by a mutation in the cationic trypsinogen gene. Nature (Genetics) 1996;41:141-5.

46. Rothstein FC, Wylie R, Gauderer MEL. Hereditary pancreatitis and recurrent abdominal pain in childhood. J Pediatr Surg 1985;20:535-7.

47. Kahler SG, Sherwood WG, Woolf D, et al. Pancreatitis in patients with organic acidemias. J Pediatr 1994;124:239-43. 


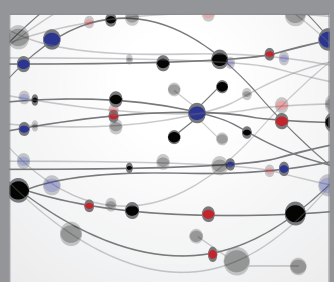

The Scientific World Journal
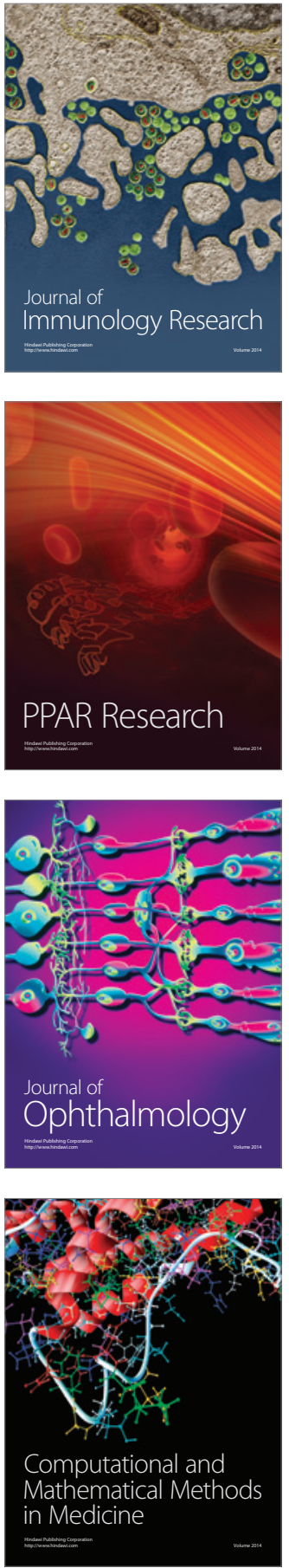

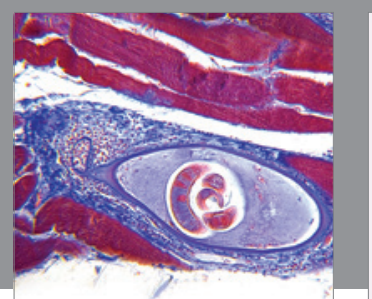

Gastroenterology Research and Practice

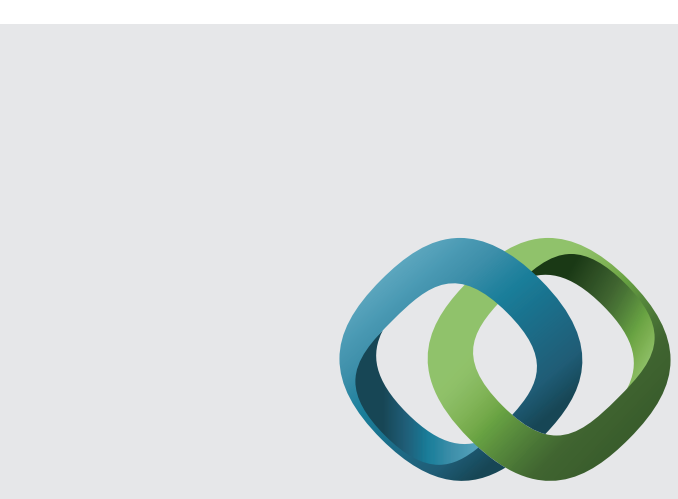

\section{Hindawi}

Submit your manuscripts at

http://www.hindawi.com
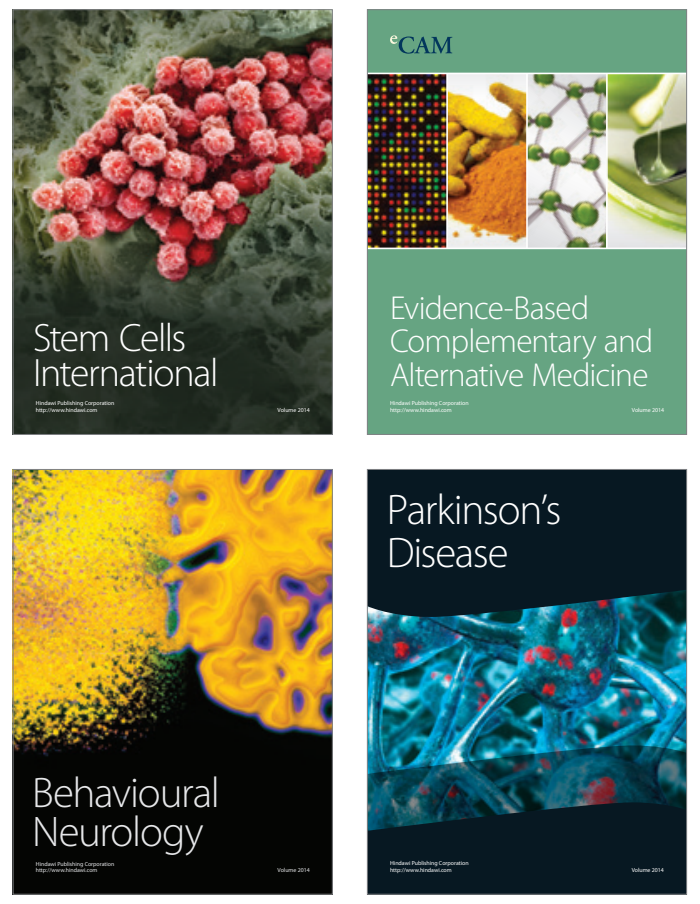
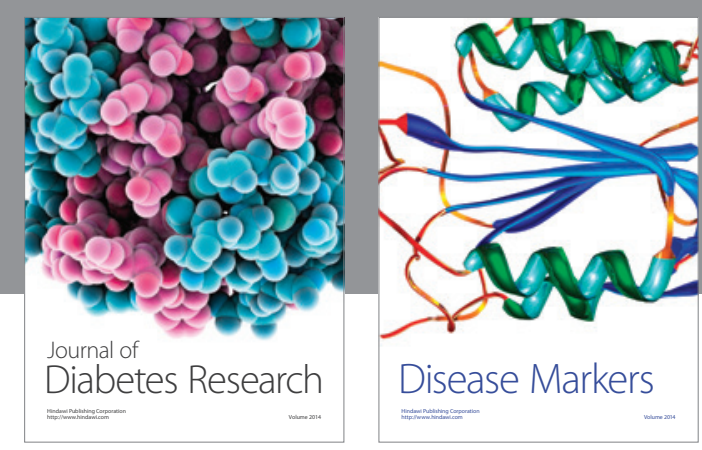

Disease Markers
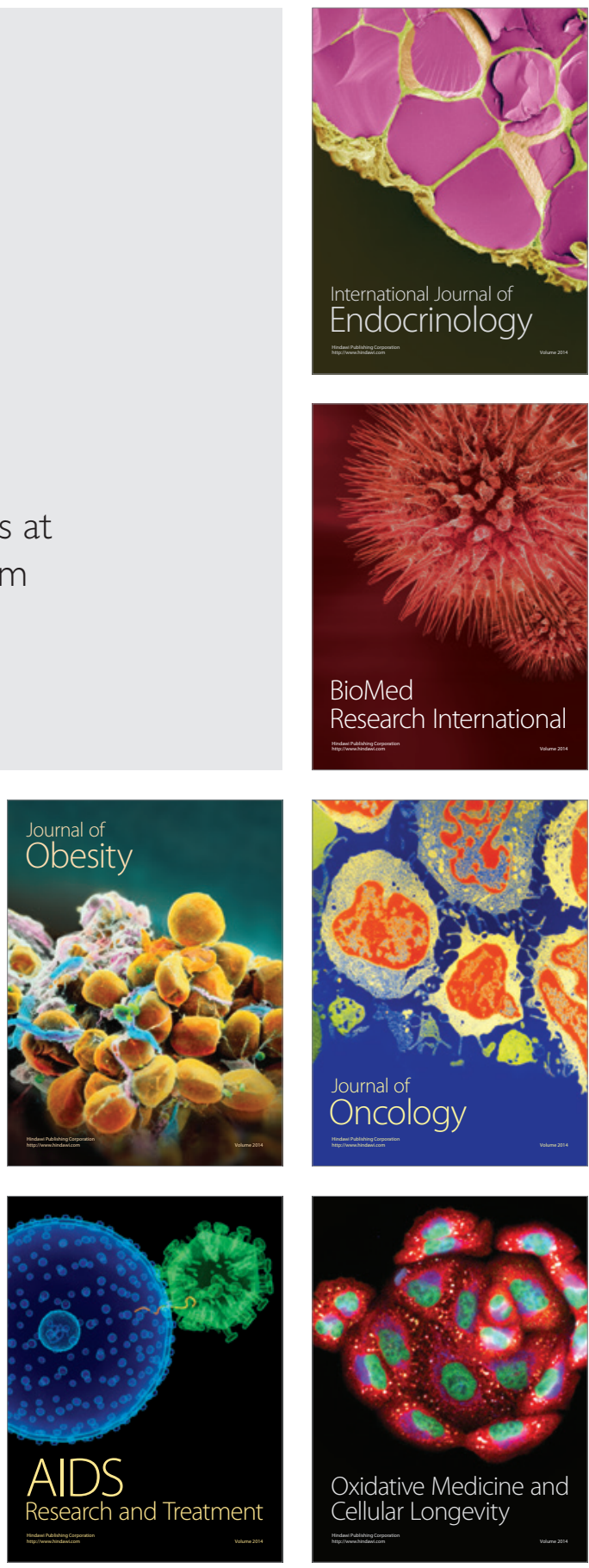